\title{
ARTEFAK PERHIASAN MANIK-MANIK ORANG HUAULU DI PULAU SERAM (Artefact Jewelry Beads of Huaulu People, Seram Island)
}

\section{Lucas Wattimena}

Balai Arkeologi Maluku Jl. Namalatu-Latuhalat, Kecamatan Nusaniwe, Kota Ambon, 97118

e-mail: lucas.wattimena@yahoo.com

\section{INFO ARTIKEL}

Histori artikel

Diterima: 10 Februari 2016

Direvisi: 8 Maret 2016

Disetujui: 17 Mei 2016

\section{Keywords:}

Artefact beaded jewelry, structure kinship,

value element

Kata kunci:

Artefak perhiasan manik-manik, struktur kekerabatan,

unsur nilai

\begin{abstract}
This paper discuss about value consist in material culture artefact beaded jewelary. The purpose of this paper is too know and understanding the value consist in material culture beaded jewelry. Method of this paper used a etnoarcheology, with technique interview, survey/observation, and literature study. Results shows that's shape and function of artefact beaded jewelry of Huaulu people used for initiation ceremonial for adult men. Beaded jewelry artefact has a kindship value. The value it's seeing in the structure of kindship it self, which function, role and position just for men only, woman can't used this beaded jewelary artefacts. It is also prove that mens role dominated (patrilineal) in cycle of Huaulu people.
\end{abstract}

\begin{abstract}
ABSTRAK
Tulisan ini membahas tentang unsur-unsur nilai yang terkandung dalam budaya bendawi artefak perhiasan manik-manik. Tujuannya adalah untuk mengetahui dan memahami unsur-unsur nilai apa saja yang terkandung dalam budaya bendawi perhiasaan manik-manik. Metode penelitian menggunakan pendekatan etnoarkeologi, dengan teknik pengumpulan data wawancara, survei dan studi pustaka. Hasil penelitian menunjukan bahwa bentuk dan fungsi perhiasan manik-manik orang Huaulu sebagai media untuk pelaksanaan upacara adat inisiasi laki-laki dewasa. Perhiasan manik-manik mengandung unsur-unsur nilai kekerabatan. Nilai kekerabatan perhiasan manik-manik dapat dilihat pada struktur kekerabatan. Dimana struktur peran, fungsi dan kedudukan perhiasan dimaksud, hanya garis laki-laki (bapak) yang menggunakan perhiasan, perempuan tidak menggunakan perhiasan. Hal ini membuktikan bahwa peran laki-laki (patrilineal) dominasi dalam siklus hidup orang Huaulu.
\end{abstract}

\section{PENDAHULUAN}

Budaya bendawi (artefak) salah satu data dari beberapa jenis data dalam mengungkapkan interaksi budaya di masa lampau. Adanya unsur budaya bendawi baru atau munculnya langgam artefak tertentu dalam suatu sistem budaya seringkali ditunjuk sebagai bukti adanya interaksi antar budaya yang diikuti dengan masuknya unsur budaya bendawi baru dalam sistem budaya tersebut (Tanudirjo, 2011 : 25). Artefak memainkan peran yang sangat penting, karena di dalamnya mengandung informasi mengenai aspek kognisi dan tingkah laku budaya manusia pendukungan budaya yang bersangkutan (Noerwidi, 2007 : 5). Konteks pada artefak juga menunjukan keberagaman kehidupan manusia masyarakat pada waktu itu (Hiscock, 2005; Tim penyusun, 1999).

Perhiasan manik-manik orang Huaulu adalah bagian dari artefak dalam pembahasan tulisan ini yang digunakan sebagai media dalam upacara pendewasaan laki-laki cidaku atau uhely. Fokus pembahasan yaitu nilai-nilai yang terkandung dalam artefak perhiasan manik-manik orang Huaulu. Tujuan penulisan adalah untuk mengetahui dan memahami nilainilai yang terkandung dalam artefak perhiasan manik-manik orang Huaulu sebagai budaya bendawi. 
Manik-manik orang Huaulu digunakan sebagai perlengkapan upacara adat pendewasaan laki-laki, yaitu cidaku atau uhely. Upacara tersebut wajib aturannya untuk anak laki-laki Huaulu yang memasuki masa pubertas. Bagi anak laki-laki yang akan menjalankan upacara dimaksud dilarang untuk berpacaran, apalagi sampai berhubungan badan atau seksualitas (Rahawarin, 2008 : 98). Upacara tersebut tergolong dalam tiga bagian besar, yaitu 1) Persiapan; 2) pelaksanaan dan 3) pemberkatan atau upacara syukuran (kahua). Pada bagian terakhir atau (ke-3) (syukuran) perhiasan manik-manik dipakai oleh laki-laki yang menjalankan proses pendewasaan.

Menurut tetua adat setempat bahwa perhiasan tersebut adalah warisan dari leluhur mereka yang diperoleh dari dulu hingga sekarang. Seluruh orang Huaulu memiliki perhiasan dimaksud. Informasi sejak kapan mereka mengenal perhiasan manik-manik, sudah tidak diketahui dengan pasti, namun yang pasti mereka adalah generasi ketiga. Artefak perhiasan manik-manik masih dapat ditemukan di setiap keluarga atau marga/mata rumah orang Huaulu (Tim penyusun, 2013; 2015).

Pengertian umum manik-manik adalah benda-benda yang biasanya berbentuk bulat di bagian tengahnya guna menghias badan atau sebuah benda. Perhiasan manik-manik dikelompokkan dalam objek khusus berdasarkan tingkat analisis (Tim Penyusun, 1999 : 79). Bentuk-bentuk dasar manik-manik terdiri dari: bentuk bulat, bentuk tong, bentuk kerucut, bentuk silinder, bentuk buah pir (pear) dengan berbagai variasinya, sedangkan bentuk khusus antara lain berbentuk cincin, bersusun, prisma, kubus, tablet berfase, dan lain-lain (Tim penyusun, 1999 : 79). Artefak perhiasan manik-manik orang Huaulu ditemukan beberapa bentuk dasar, yaitu bentuk bulat, bentuk buah dan pir bentuk tong. Variatif bentuk dasar tersebut lebih didominasi oleh ketiga varian bentuk tersebut dengan susunan saling bergantian bahkan hanya satu bentuk yang dominasi.

Hasil ekskavasi pada permukiman Pra Sriwijaya di kawasan Situs Air Sugihan di pantai timur Sumatera menemukan beberapa artefak manikmanik batu carnelian dan manik-manik yang didatangkan dari India Selatan (Arikamendu) pada periode awal sejarah. Melihat dari karakter temuan tersebut diduga merupakan hasil dari perdagangan (Indradjaja, dkk. 2015 : 43).

Belwood (2000 : 431) berpendapat manik-manik dari batu agate dan carnelian juga ditemukan di situs penguburan dalam tempayan pada Leang Buidane, Pulau Salebabu kelompok Talaud di sebelah timur Indonesia. Manik-manik kaca ditemukan di Gua Uttamdi, Pulau Kayoa.

Lokasi penelitian pada komunitas adat orang Huaulu atau suku Huaulu yang mendiami wilayah pegunungan Pulau Seram bagian utara. Pendekatan penelitian secara kualitatif dengan kajian etnoarkeologi (Tanudirjo, 2009 :3-4) dibagi menjadi tiga kelompok; pertama, disebutkan kajian etnografi yang secara informal memberikan informasi kepada ahli arkeologi. Disebut etnoarkeologi informal kalau pengamatan etnografi dilakukan hanya sekilas saja tetapi dimaksudkan untuk kepentingan arkeologi. Kedua, etnoarkeologi yang mengkaji secara khusus salah satu aspek tertentu dari budaya yang masih hidup, misalnya 
mata pencaharian, teknologi, atau religi. Ketiga, etnoarkeologi yang menelaah secara mendalam seluruh budaya masyarakat yang masih hidup sebagai konteks penciptaan budaya bendawi.

Ahli lainnya Schiffer dalam Tanudirjo (2009 : 3) menyatakan "etnoarkeologi adalah kajian tentang budaya bendawi dalam sistem budaya yang masih ada untuk mendapatkan informasi, khusus maupun umum, yang dapat berguna bagi penelitian arkeologi". Etnoarkeologi menelisik hubungan antara tindakan manusia dan budaya bendawi di masa kini untuk menyediakan prinsip-prinsip yang dibutuhkan dalam kajian tentang masa lampau. Analisis perhiasan biasanya hanya berkaitan dengan aseksoris, digunakan atau dipakai manusia sebagai alat pelengkap dekoratif (Tim penyusun, 1999).

\section{PEMBAHASAN}

Artefak perhiasan manik-manik orang Huaulu adalah sebuah struktur simbolik. Artefak sebagai media dalam tatanan struktur sosial budaya orang Huaulu, dimana nilai struktur yang terkandung di dalamnya menyangkut peran dan kedudukan laki-laki dalam sistim hidup orang Huaulu (kelahiran sampai kematian). Proses laki-laki dewasa ketika akan menjadi dewasa, siap secara jasmani dan rohani dalam siklus sistem sosial budaya orang Huaulu mampu memberikan respon-respon terbaik dalam kesatuan kelompok/suku sebagai orang Huaulu.

Manik-manik adalah bendabenda yang biasanya berbentuk bulat dan memiliki lubang di bagian tengahnya guna menghiasi badan atau sebuah benda. Umumnya pemakaian manik-manik sebagai perhiasan dengan cara dironce atau dirangkai satu persatu pada seutas benang atau bahan lain, sehingga umumnya berbentuk perhiasan kalung atau gelang (Penyusun, 1999 : 39). Manikmanik orang Huaulu adalah material dasar dalam pembahasan dimaksud, maka analisis artefak pun diperlukan dalam mengungkap hubungan budaya dan benda. Secara umum terdapat dua jenis analisis; 1) analisis khusus menekankan pada ciri-ciri fisik artefak, 2) analisis umum menitikberatkan pada hubungan antar data arkeologi.

\section{Perhiasan manik-manik dengan hiasan mata rantai berbentuk bulat}

Pada tipe ini varian warna yang dapat kita temukan antara lain; putih mutiara, hitam, oranye, coklat, hijau lumut, merah maron, biru laut dan kuning muda. Varian warna tersebut tersusun rapi membentuk rantai. Warna pada mata rantai adalah warna asli dari bahan (dasar) perunggu. Pada mata rantai terdapat ukiran tulisan kanji atau sastra Cina.

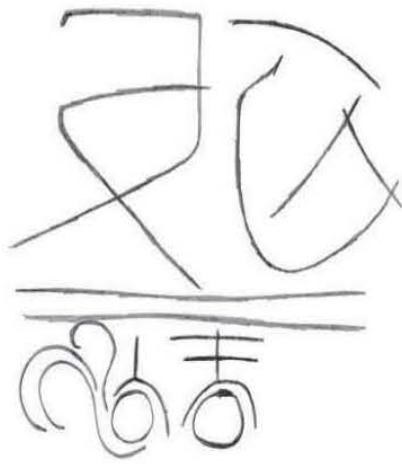

Gambar 1. Tulisan pada mata rantai perunggu perhiasan manik-manik (dokumentasi Balai Arkeologi Ambon)

Bagian dalam bulatan mata rantai terdapat semacam biji yang ketika bergerak maka akan berdentangan dan mengeluarkan bunyi (seperti lonceng). Tipe ini memiliki bentuk perhiasan bulat dan bahan dasarnya terdiri dari kayu, tulang, perunggu dan batu. 


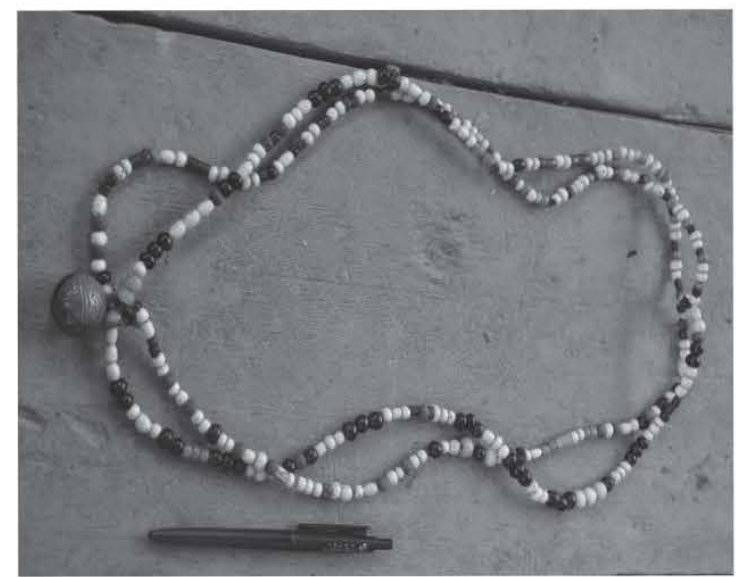

Gambar 2. Perhiasan manik-manik Orang Huaulu, Seram Utara, Maluku Tengah (dokumentasi Balai Arkeologi Ambon)

Perhiasan manik-manik dengan hiasan mata rantai bulat seperti lonceng

Bahan dasar lebih nominan bahan batu, dan tulang. Varian warna pun lebih corak terang, seperti biru laut, hijau, hitam, putih. Mata rantai bahan dasar perunggu dengan warna asli perunggu. Motif pada mata rantai sudah tidak kelihatan, karena umur yang sudah tua, sehingga sudah terkelupas. Namun yang pasti pada motif hiasan mata rantai ini lebih kepada corak motif garis linear, tidak memiliki tulisan.

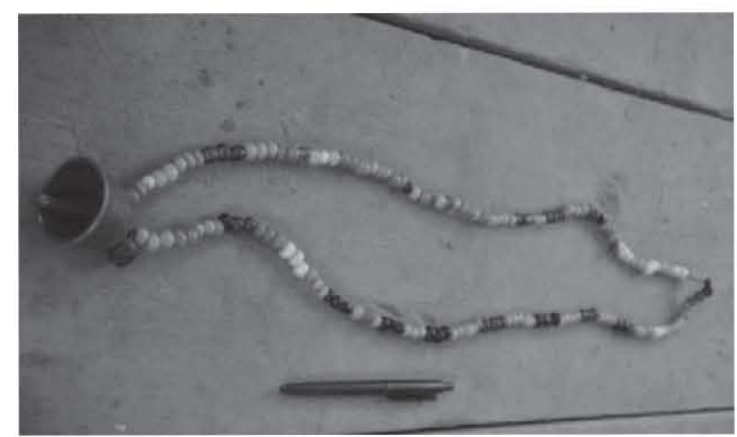

Gambar 3. Tipe (2) perhiasan Manik-Manik Orang Huaulu, Seram Utara Maluku Tengah. Perhiasan memiliki hiasan mata rantai bulat seperti lonceng. (dokumentasi Balai Arkeologi Ambon)

Perhiasan manik-manik orang Huaulu adalah sebagai media atau alat perlengkapan upacara adat, salah satunya pendewasaan laki-laki. Seperti yang telah dijelaskan sebelumnya bahwa perhiasan ini dipakai pada saat proses terakhir dari ritual uhely (ucapan syukur dengan tanda tarian maku-maku). Perhiasan ini lebih memiliki fungsi sebagai kehebatan atau penampilan seseorang dalam suatu ikatan kelompok, karena ditinjau berdasarkan bukti arkeologi:

a) Bahan berasal dari luar Pulau Seram. Hasil pengamatan dan wawancara tidak menemukan orang Huaulu yang mampu membuat perhiasan dimaksud. Menurut mereka artefak tersebut adalah pemberian leluhur mereka.

b) Teknologi pada proses pembuatan dan pewarnaan.

Pemahaman dan pandangan orang Huaulu terhadap perhiasan manik-manik tersebut adalah nilai simbolik terhadap ritual pendewasaan orang Huaulu. mengapa demikian, karena merupakan nilai tambahan asesoris. Oleh Geertz (Marzali, 2014) kultur sebagai jaringan atau sistem makna yang terjandung dalam simbol. Perlengkapan artefak perhiasan manik-manik ditaruh di sebuah wadah porselen dengan hiasan kepala, kain berang, hiasan bulu burung kakatua oranye. Kultur terdiri dari struktur makna yang terbentuk secara sosial yang menjadi pedoman bagi anggota masyarakat untuk menafsirkan pengalaman hidupnya dan untuk mewujudkan kelakuannya. Semua perlengkapan benda tersebut adalah wujud sistim interaksi dan integrasi orang Huaulu di luar kelompoknya. Proses perdagangan sebagai salah satu interaksi dan integrasi dimaksud (Pattikayhatu, 2012; Huwae, 2010; Suroto, 2009; Huliselan, 2012; Handoko, 2007; Tanudirjo, 2011; O"Connor et al, 2005) dan proses perkawinan (Rahawarin, 2008 : 151). 


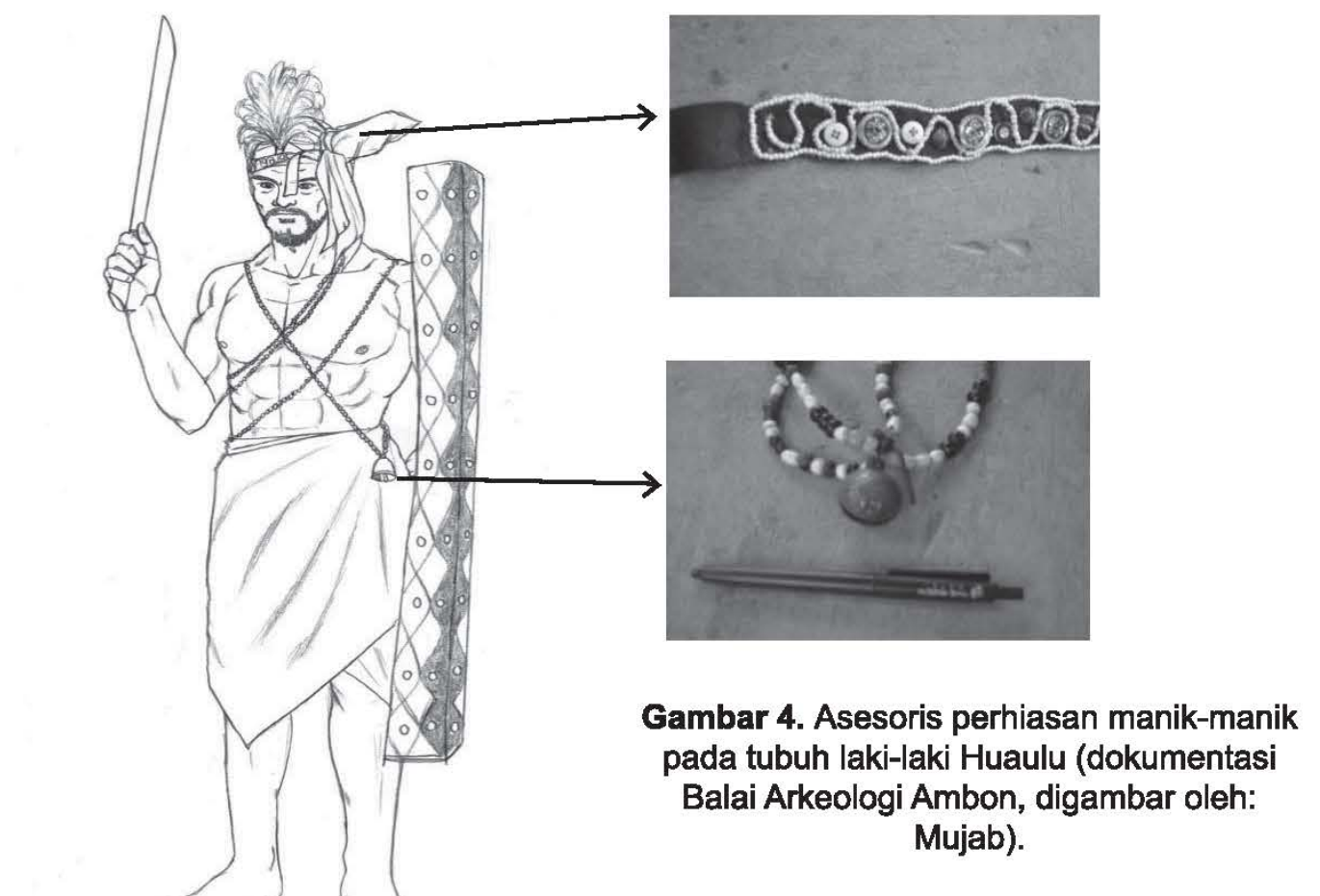

Perhiasan manik-manik dipakai pada kedua sisi badan kiri dan kanan dengan posisi lonceng pada perhiasan berada di depan kiri (pinggang kiri muka) dan kanan belakang (pinggang kanan belakang), dengan tujuan agar dentukan bunyi terdengar nyaring seiring langkah kaki pada proses tarian

dilaksanakan. Asesoris perhiasan manik-manik dipakai bersamaan dengan asesoris lain, prang salawaku, cidaku. Ikat kepala dengan hiasan burung kakatua oranye secara holistik memiliki fungsi dan makna kehebatan berpenampilan.

\section{PENUTUP}

Orang Huaulu di wilayah Pegunungan Pulau Seram bagian utara, Maluku Tengah memiliki peninggalan artefak perhiasan manikmanik sejak dari leluhur hingga sekarang ini. Bentuk dan fungsi artefak perhiasan manik-manik orang Huaulu berupa kelengkapan asesoris untuk pelaksanaan upacara adat inisiasi

kaum laki-laki dewasa. Struktur simbolik artefak perhiasan manikmanik memiliki nilai interaksi dan integrasi serta kekerabatan. Perhiasan manik-manik hanya boleh dipakai oleh kaum laki-laki saat proses inisiasi, kaum perempuan tidak menggunakan kelengkapan perhiasan dimaksud. 


\section{DAFTAR PUSTAKA}

Bellwood, Peter. 2000. Prasejarah Kepulauan Indo-Malaya. Edisi Revisi. Jakarta. PT. Gramedia Pustaka Utama.

Handoko, Wuri. 2007. "Aktifitas Perdagangan Lokal di Kepulauan Maluku Abad 1519 M". Kapata Arkeologi Vol. 3 (4). 100-120. Balai Arkeologi Ambon.

Hiscock, Pieter. 2005. Artefact; Evaluating The Technological Squences. The Archaelogy of Aru Islands, Eastern Indonesia. Sue O' Connor, Matthew Springgs, Peter Veth. Canberra. ANU. Page 205-234.

Huliselan, Mus. 2012. "Perdagangan Internasional; Pengaruhnya Terhadap Sistem Nilai Budaya orang Maluku". Kapata Arkeologi Vol 8(1), 9-24. Balai Arkeologi Ambon.

Huwae, Andrew. 2010. "Kajian Historis Tentang Sistem Perdagangan di Maluku Tengah Pada Abad ke 19". Kapata Arkeologi Vol. 6 (10). 113-120. Balai Arkeologi Ambon.

Indradjaja, Agustijanto, Taim Eka Putrina, Arif Jhon. 2015. "Permukiman Pra Sriwijaya di Kawasan Situs Air Sugihan, Pantai Timur Sumatra" dalam Bambang Budi Utomo (Ed), Kehidupan Purba di Lahan Gambut. Surakarta: PT. Sinergi Media.

Mansyur, Syahruddin. 2011. "'Jejak Tata Niaga Rempah-Rempah Dalam Jaringan Masa Perdagangan Masa Kolonial di Maluku". Kapata Arkeologi Vol. 7 (13) 20-39. Balai Arkeologi Ambon.

Marzali, Amri. 2014. "Memajukan Kebudayaan Nasional Indonesia". Humaniora Vol 26 (3). 251-265. Yogyakarta. Fakultas IImu Budaya, Universitas Gadjah Mada.

Noerwidi, Sofyan. 2007. "Beberapa Seni Kriya Elemen Penanda Kehadiran Austronesia di Kepulauan Indonesia". Makalah disampaikan dalam rangka Lustrum ke-9 FIB, Yogyakarta. Universitas Gadjah Mada.

Penyusun, Tim. 1999. Metode Penelitian Arkeologi. Jakarta: Pusat Penelitian Arkeologi Nasional.

Penyusun, Tim. 2013. Laporan Penelitian Arkologi Permukiman Orang Huaulu di Seram Utara, Kabupaten Maluku Tengah, Propinsi Maluku. Ambon. Balai Arkeologi Ambon.

Rahawarin, Djamal. 2008. Perubahan Sosial Budaya pada Komunitas Adat Huaulu di Seram Utara Kabupaten Maluku Tengah. Program Pascasarjana Program Studi Sosiologi Universitas Pattimura.

Suroto, Hari. 2009. “Fungsi Kulit Kerang Cypraea Moneta dalam Perdagangan di Pegunungan Tinggi Papua”. Kapata Arkeologi (Jurnal Arkeologi Wilayah Maluku dan Maluku Utara). Vol 5 (9), 96-102. Balai Arkeologi Ambon.

Tanudirjo, Daud. 2009. "Memikirkan Kembali Etnoarkeologi". Jurnal Arkeologi Papua. Vol. 1 (2), 1-15. Balai Arkeologi Jayapura. 
Tanudirjo, Daud. 2011. "Interaksi Austronesia-Melanesia; Kajian Interprestasi Teoritis". Austronesia dan Melanesia di Nusantara: Mengungkap Asal Usul dan Jati Diri dari Temuan Arkeologis. Yogyakarta: Penerbit Ombak. HIm. 23-42.

Tim Penelitian. 2013. Laporan Penelitian Permukiman Orang Huaulu di Seram Utara, Kabupaten Maluku Tengah, Propinsi Maluku. Balai Arkeologi Ambon.

Tim penelitian. 2015. Laporan Penelitian Cultural Resourches Management (CRM) Orang Huaulu, Seram Utara, Kabupaten Maluku Tengah, Propinsi Maluku. Balai Arkeologi Ambon. 